\title{
Molecular Architecture and Function of Matrix Adhesions
}

\author{
Benjamin Geiger ${ }^{1}$ and Kenneth M. Yamada ${ }^{2}$ \\ ${ }^{1}$ Department of Molecular Cell Biology, Weizmann Institute of Science, Rehovot 76100, Israel \\ ${ }^{2}$ Laboratory of Cell and Developmental Biology, National Institute of Craniofacial and Dental Research, \\ National Institutes of Health, Bethesda, Maryland 20892 \\ Correspondence: benny.geiger@weizmann.ac.il; kenneth.yamada@nih.gov
}

Cell adhesions mediate important bidirectional interactions between cells and the extracellular matrix. They provide an interactive interface between the extracellular chemical and physical environment and the cellular scaffolding and signaling machinery. This dynamic, reciprocal regulation of intracellular processes and the matrix is mediated by membrane receptors such as the integrins, as well as many other components that comprise the adhesome. Adhesome constituents assemble themselves into different types of cell adhesion structures that vary in molecular complexity and change over time. These cell adhesions play crucial roles in cell migration, proliferation, and determination of cell fate.

$W^{10}$ ith the emergence of metazoan life approximately 600 million years ago, new biological mechanisms arose during the evolution of multicellular organisms with a defined body plan. These mechanisms of cell adhesion are a fundamental feature of all metazoans, from sponges to humans; they enable cells to attach to each other or to an extracellular matrix (ECM), cementing them together and organizing them into a coherent whole. The formation of adhesions and the regulation of their dynamics are crucial for embryogenesis, immune cell function, and wound repair, but they also contribute to disease, including cancer invasion and metastasis, or immune disorders (Hay 1991; Hynes 2002; Berrier and Yamada 2007; Alberts et al. 2008; Mory et al. 2008; Dubash et al. 2009; Manevich-Mendelson et al. 2009; Svensson et al. 2009; Wolfenson et al. 2009a). Adhesive interactions can occur with remarkable temporal and spatial precision. As illustrated in Figure 1, they not only link cells together into functional tissues and organs, but they also convey to the adhering cells accurate positional information concerning their cellular and extracellular environment. This information can, in turn, affect all facets of the cell's life-its proliferation, differentiation, and fate. In addition to responding to the matrix, cell adhesions can actively remodel and restructure the ECM, driving a reciprocal, bidirectional interaction between the cell and its surrounding matrix. These two fundamental aspects of cell-ECM adhesion-physical/ structural roles and environmental sensing/ signaling, as well as the dynamic molecular

Editors: Richard Hynes and Kenneth Yamada

Additional Perspectives on Extracellular Matrix Biology available at www.cshperspectives.org

Copyright (C) 2011 Cold Spring Harbor Laboratory Press; all rights reserved; doi: 10.1101/cshperspect.a005033

Cite this article as Cold Spring Harb Perspect Biol 2011;3:a005033 
B. Geiger and K.M. Yamada

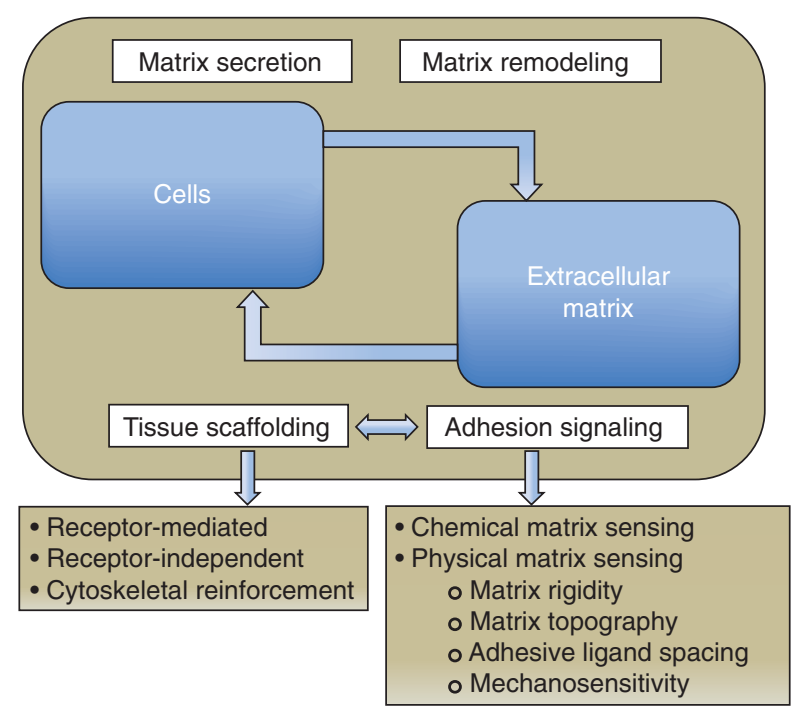

Figure 1. Schematic illustration highlighting the dynamic cross talk between cells and the extracellular matrix (ECM). Cells secrete and remodel the ECM, and the ECM contributes to the assembly of individual cells into tissues, affecting this process at both receptor and cytoskeletal levels. Adhesion-mediated signaling, based on the cells' capacity to sense the chemical and physical properties of the matrix, affects both global cell physiology and local molecular scaffolding of the adhesion sites. The molecular interactions within the adhesion site stimulate, in turn, the signaling process, by clustering together the structural and signaling components of the adhesome.

interrelationships between them-will be the primary subjects of this article.

We will also describe the functional molecular architecture of cell-matrix adhesions, highlighting the structure-function relationships between the numerous components of cell adhesions that mediate or modulate numerous cell adhesive, migratory, and regulatory processes. We will discuss the mechanisms underlying the scaffolding and sensing processes generated at integrin-mediated adhesions, considering them along two major multiscale conceptual trajectories: molecular complexity and time- that is, a hierarchy of complexity that spans the range from molecules to multimolecular complexes in mature adhesions, as well as the temporal progression of structures during the assembly and maturation of matrix adhesions, from initial cell-matrix recognition to the formation, maturation, and reorganization of cytoskeleton-associated matrix adhesions.

\section{MOLECULAR AND STRUCTURAL DIVERSITY OF THE EXTRACELLULAR MATRIX}

The ECM serves as a substrate to which cells attach via cell-matrix adhesions, but it is also initially constructed and remodeled by such adhesions (Hay 1991; Alberts et al. 2008). The ECM is highly diverse, ranging from loose connective tissue to densely packed tendons and sheets of basement membrane.

\section{Chemical Composition}

Depending on the type of matrix, the components of ECMs can vary widely. For example, fascia and tendons contain high levels of collagen I with various minor components, whereas basement membranes contain substantial amounts of collagen IV, laminin, perlecan, and other components (Ricard-Blum 2011; Yurchenco 2011). The molecular composition and the organization of the ECM's constituent 
molecules play major roles in the responses of cells to their local matrix microenvironment. Of particular interest in this respect are the specific associations of multiple growth factors (e.g., fibroblast growth factors, transforming growth factors, heparin-binding epidermal growth factor, and others) with the matrix, and their capacity to locally stimulate the adherent cells (Gospodarowicz et al. 1980; Hay 1991; Hynes 2009; Sarrazin et al. 2011; Sheppard and Munger 2011). These findings suggest that signaling from the ECM can be triggered by two major mechanisms: the activation of intracellular signaling complexes through their recruitment to the adhesion site, and direct stimulation of specific growth factor receptors by ECM-immobilized growth factors.

\section{Dimensionality}

The "dimensionality" of each ECM is another key contributor to cell-matrix function. Cells adhering to standard tissue culture surfaces and basement membranes often flatten and adhere tightly to the two-dimensional (2-D) surfaces. In contrast, cells in connective tissue or inside organs are generally embedded within a three-dimensional (3-D) environment (Elsdale and Bard 1972; Cukierman et al. 2001; Nelson and Bissell 2006). In a strongly fibrillar 3-D environment, however, cells appear to recognize and form distinctive adhesions with "one-dimensional" fibrils or linear patterns of ECM (Doyle et al. 2009). Cells can also respond to the micro-topography or even nano-topography of a surface to which they adhere (Curtis and Wilkinson 1997; Cukierman et al. 2001; Geiger et al. 2001; Baharloo et al. 2005; Grossner-Schreiber et al. 2006; Vogel et al. 2006; Geblinger et al. 2010). Furthermore, the spacing between individual ECM ligand molecules (e.g., the Arg-Gly-Asp-containing peptide that binds to integrin) plays a key role in the adhesion process. Specifically, effective assembly of cytoskeleton-bound focal adhesions depends on an inter-ligand spacing of $<60-140$ nanometers (Massia and Hubbell 1991; Cavalcanti-Adam et al. 2007; Geiger et al. 2009). The physical dimensionality of different microenvironments can play critical roles in biological activities, regulating cell morphology, rates of adhesion, migration, proliferation, and biosynthesis (Nelson and Bissell 2006; Yamada and Cukierman 2007; Geiger et al. 2009; Grinnell and Petroll 2010).

\section{Mechanical Properties}

In addition to composition and dimensionality, a third key element of an ECM involves its mechanical properties. Several important features are rigidity (elasticity or compliance), mechanical heterogeneity in terms of local porosity and cross-linking, and overall anisotropy. For example, human tumors are often surrounded by a matrix with high local concentrations of collagen encircling the tumor, and the tissue is more rigid and oriented, or isotropic, than adjacent connective tissues-a response of the surrounding tissue termed desmoplasia (Beacham and Cukierman 2005; Nelson and Bissell 2006; Butcher et al. 2009; Klein et al. 2009). Such mechanical properties of a matrix can have major regulatory effects on the choice of stem cell fate, proliferation rate, pattern of gene expression, migration, and tumor progression (Engler et al. 2007; Discher et al. 2009; Levental et al. 2009; Schwartz 2010). In fact, rigidity sensing can be a cell-type specific property, and cells (e.g., fibroblasts, myocytes, or neurons) grow optimally on adherent surfaces that match the cells' intrinsic elasticity (Discher et al. 2005). Interestingly, fibroblasts isolated from sites of desmoplasia close to tumors can retain their ability to produce an ECM with altered matrix morphology and with distinctive effects on cells, even in the absence of the tumor (Amatangelo et al. 2005); such activated fibroblasts have been implicated in epithelial cell cancer progression.

\section{MOLECULAR DIVERSITY OF MATRIX ADHESION RECEPTORS}

In this article, we place major emphasis on integrin-mediated adhesions, but it is important to note that there are multiple adhesive interactions mediated by nonintegrin receptors. 
Some of these molecular interactions are discussed below, but we first discuss a special class of adhesion-related structures known as the pericellular matrix, which is highly enriched with glycosaminoglycans such as hyaluronan (Zimmerman et al. 2002). This cell-bound matrix can be quite thick (up to several micrometers in certain cell types such as chondrocytes), covering the entire cell surface. The structure and function of this matrix layer are elusive because of its transparency and high water content, but its prominence in cells and its thickness relative to the dimensions of transmembrane integrins suggest that the first contacts between cells and the ECM involve this pericellular matrix. The formation of initial cell-substrate adhesions was monitored in living cells by total internal reflection microscopy, visualizing the pericellular matrix by labeling with fluorescent quantum dots. The quantum dots marking the matrix accumulate near the substrate well before the establishment of focal adhesions. Furthermore, removal of this coat by hyaluronidase alters these early cell-matrix adhesive interactions (Cohen et al. 2006).

The integrin family of matrix protein receptors plays a central role in the formation, maturation, and function of a variety of cell adhesions. Integrins are heterodimers with one $\alpha$ and one $\beta$ subunit that bind with a specificity governed by each of the subunits to ECM molecules including collagens, laminins, fibronectin, vitronectin, and fibrin (Hynes 2011). The types of integrins in adhesions can switch as they mature, which may be related to distinct functions. For example, $\alpha v \beta 3$ and $\alpha 5 \beta 1$ are involved in forming the initial contacts required for adhesion formation and signaling: $\alpha 5 \beta 1$ can be activated by force to mediate firm adhesion to synergistic sites in fibronectin; for example, when fibronectin is immobilized (Friedland et al. 2009), but then $\alpha v \beta 3$ remains to provide firm anchorage in focal adhesions (Pankov et al. 2000; Zamir et al. 2000). On the other hand, $\alpha 5 \beta 1$ is initially present in focal adhesions formed on a fibronectin substrate, along with $\alpha v \beta 3$, but is lost from these adhesions unless the fibronectin is physically immobilized, in which case it forms exaggerated $\alpha 5 \beta 1$-containing focal adhesions (Katz et al. 2000; Pankov et al. 2000). Interestingly, if the same cells adhere to fibronectin or vitronectin via $\alpha 5 \beta 1$ or $\alpha \mathrm{v} \beta 3$, respectively, they display very different patterns of cell spreading and FA distribution on each matrix substrate. Cells adhering to fibronectin spread much more than those adhering to vitronectin, and their FAs are located throughout the ventral membrane, compared to the more peripheral distribution of FAs in cells on vitronectin (Fig. 2).

Naturally, given the rich variety of integrin $\alpha$ and $\beta$ chains, there are multiple integrin heterodimers with both distinct and overlapping binding functions; this diversity includes the differential capacity of specific integrins to recruit cytoplasmic molecular partners and interact with the actin cytoskeleton. Elucidating these differences in integrin-specific adhesion complexes will provide many opportunities for identifying the basis of ECM ligand-specific responses of cells; for example, in collagen-, fibronectin-, or laminin-rich environments.

\section{Forms of Integrin-Mediated Adhesions}

A particularly noteworthy feature of integrinbased adhesions, even within the same cells, is their ability to form morphologically, molecularly, and dynamically diverse types of adhesion structures. In addition to the dimensionality conferred by the particular topography of the extracellular matrix, integrin-mediated interactions with the ECM can trigger the formation of different forms of matrix adhesions, which can partially overlap or segregate into mutually exclusive adhesions, as illustrated in Figure 3. As discussed below, some of these adhesions can evolve or mature into other forms of matrix adhesions.

Distinct types of cell adhesions include: (1) classical focal adhesions (Fig. 3A-E), typically generated by interaction with a flat, rigid surface; such adhesions are usually several square micrometers in size, located at the ends of actin stress fibers, and stimulated by the small GTPase RhoA (Dubash et al. 2009; Geiger et al. 2009). Actin filaments at these sites were shown to be colinear with extracellular fibronectin fibrils, 

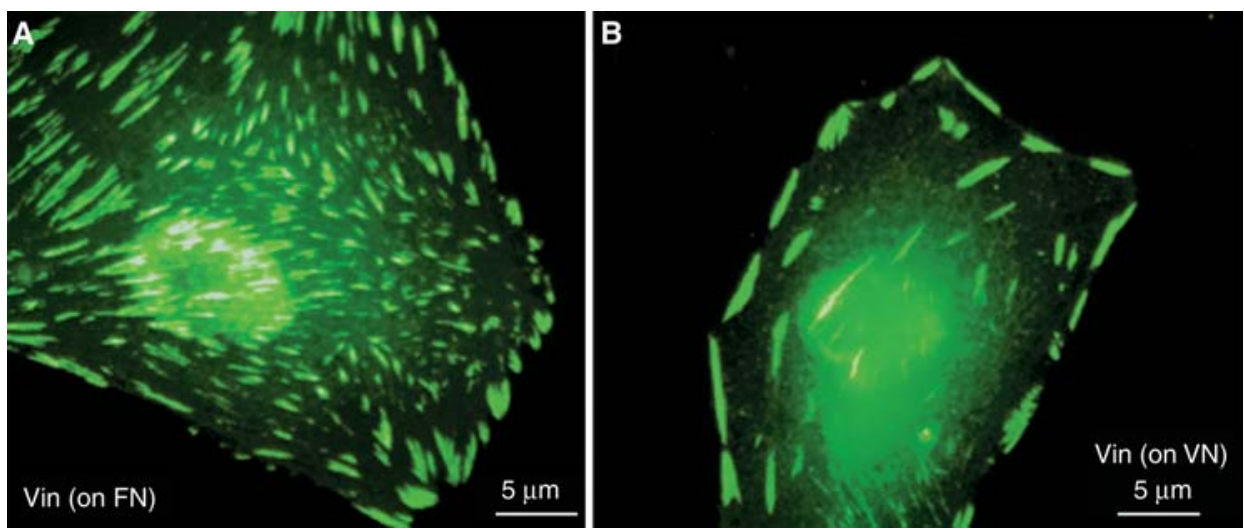

Figure 2. Differential effects of different matrices on fibroblast spreading and FA formation. This figure shows morphological and molecular differences between integrin adhesions formed in response to adhesion to different ECM matrices. Vinculin (Vin)-labeled adhesions (green) are shown following adhesion of fibroblasts to fibronectin (FN) via the $\alpha 5 \beta 1$ integrin, or to vitronectin (VN) via the $\alpha \mathrm{v} \beta 3$ integrin. Notice that VN induces less cell spreading compared to cells adhering to FN, and that the distribution of FAs is largely peripheral. Original images for this panel were provided by Baruch Zimerman.

suggesting that the two are tightly linked mechanically (Singer 1979); (2) dotlike nascent adhesions and focal complexes (Fig. 3C-E), short-lived adhesions that can transform into focal adhesions, both formed along lamellipodial protrusions, and the latter induced by Rac1 (Nobes and Hall 1995; Rottner et al. 1999; Choi et al. 2008); (3) elongated fibrillar adhesions (Fig. 3B), enriched under the central areas of cells and formed mainly along matrix fibrils such as fibronectin (Chen et al. 1985; Damsky et al. 1985; Zamir et al. 2000); and (4) podosomes or invadopodia (Fig. 3F-G), small, ringlike adhesions formed around an actin bundle, apparently anchoring it to the membrane, or thin membranous protrusions associated with an actin-cortactin core, respectively (Spinardi and Marchisio 2006; Block et al. 2008; Gimona et al. 2008; Caldieri et al. 2009; Poincloux et al. 2009). Podosomes are prominent in different monocyte derivatives (e.g., osteoclasts, macrophages, and dendritic cells). They can assemble into large, beltlike superstructures, and are implicated in matrixmodulating activities (e.g., bone resorption by osteoclasts [Geblinger et al. 2010] and matrix invasion by a variety of cancer cells [Gimona et al. 2008]). Invadopodia are particularly characteristic of invasive, transformed cells that invade by degrading the ECM. Although podosomes and invadopodia can both mediate cell invasion into the ECM, they appear to differ in the localization of vinculin and in their membrane dynamics (Artym et al. 2010).

Although cells frequently display wellformed adhesions in vitro, rapidly migrating cells can sometimes display few distinct adhesions, except for diffuse adhesive zones in which broad expanses of plasma membrane approach to within $30 \mathrm{~nm}$ of the substrate (Izzard and Lochner 1976; Couchman and Rees 1979; Huang et al. 2003; Estrada-Bernal et al. 2009). These close contacts or close adhesions appear to be relatively diffusely organized, and do not form the tight adhesions to the migratory surface that would impede rapid migration (Couchman and Rees 1979; Huang et al. 2003; Estrada-Bernal et al. 2009).

\section{Adhesions in Three-Dimensional Environments}

Cells in 3-D environments create a variety of adhesions. Classically, the dense plaques of smooth muscle (Small et al. 1986; Wang et al. 1998) form firm, integrin-based adhesions 


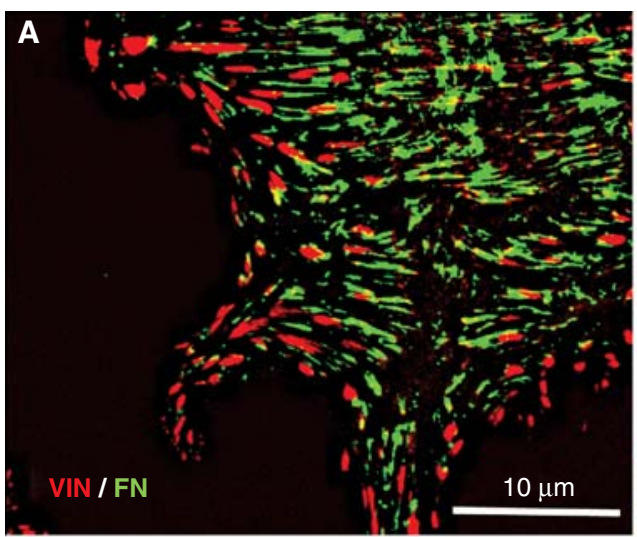

$\mathrm{FX}$

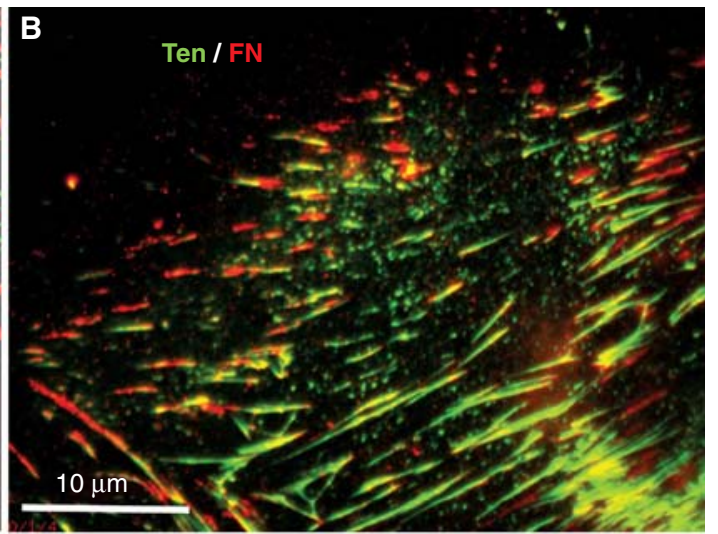

FX $\mathrm{FX}$
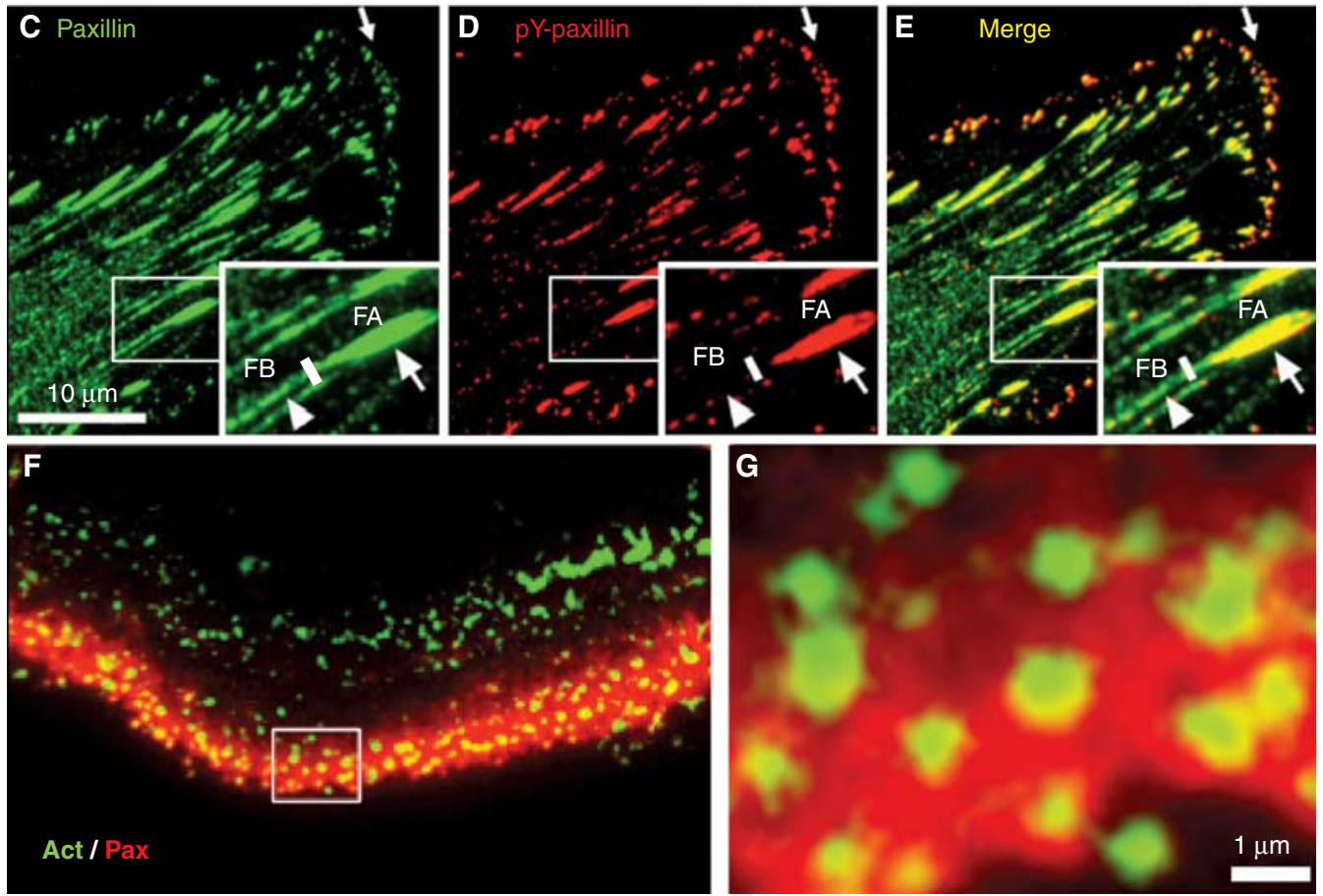

Figure 3. Immunofluorescence images of different types of cell adhesions. (A) Fibronectin (FN) fibrils in human foreskin fibroblasts, despite their capacity to induce FA formation, are generally excluded from bona fide FAs; vinculin (red) and FN (green). (B) In contrast, FN fibrils are primarily associated with tensin-rich fibrillar adhesions; tensin (green) and $\mathrm{FN}$ (red). (C-E) Major forms of integrin adhesions formed by cultured porcine aortic endothelial cells and some of their molecular characteristics, in an endothelial cell labeled for paxillin ( $C$ : green) and tyrosine-phosphorylated paxillin ( $D$ : pY-paxillin, red), and the merged image $(E)$. In these images, three major forms of integrin adhesions are detected: dotlike focal complexes (FX) located primarily at the cell's leading edge, "classical" focal adhesions (FA), and fibrillar adhesions (FB) located near FAs but more toward the cell center, in which FN fibrils are prominent. Interestingly, the three types of cell adhesion differ in their molecular properties: In FX, paxillin is highly phosphorylated (about threefold higher than in FAs), whereas no paxillin phosphorylation is detected along FB (see white arrowheads). Additional molecular differences include, for example, the absence of zyxin from FXs, and selective enrichment of $\alpha 5 \beta 1$ and $\alpha v \beta 3$ integrins in FB and FA, respectively. $(F)$ and $(G)$ show another form of integrin adhesion, podosomes, formed in this case by cultured osteoclasts. (See facing page for legend.) 
Functional Architecture of Matrix Adhesions

linking the actin cytoskeleton to the ECM. In addition, endothelial cells at sites of high hydrodynamic stress in blood vessels form structures similar to FAs (Davies et al. 1994; Girard and Nerem 1995). In 3-D matrices from which cells have been detergent-extracted, and in the loose craniofacial matrix in which embryonic cells migrate in vivo, long, slender 3-D matrix adhesions appear to represent an in vivo composite of focal and fibrillar adhesion components (Cukierman et al. 2001). The full diversity of adhesion morphologies, and their functions in vivo in a wide range of tissues, remain to be characterized.

\section{Nonintegrin ECM Receptors}

Cell surface receptors for ECM molecules other than integrins can also play major roles in cellmatrix interactions. DDR1 (discoidin domain receptor 1) and DDR2 are tyrosine kinase receptors that bind to native collagens and can play integrin-independent roles in signaling, cell adhesion, proliferation, and matrix remodeling (Vogel et al. 2006; Heino et al. 2009). CD44 and RHAMM bind the widely distributed glycosaminoglycan hyaluronan and can stimulate cell adhesion, proliferation, migration, invasion, and matrix assembly (Turley et al. 2002; Pure and Assoian 2009). Even though it is a transmembrane adhesion receptor, CD44 can be cleaved from the cell surface to become a component of the ECM (Cichy and Pure 2003). In addition, integrin-mediated interactions may be preceded by adhesions via other receptors such as selectins, which mediate the "rolling adhesion" of leukocytes on endothelial cells prior to firm, integrin-mediated adhesion (Tedder et al. 1995; Vestweber and Blanks 1999; Ley and Kansas 2004).

\section{MOLECULAR AND STRUCTURAL COMPLEXITY OF THE INTEGRIN ADHESOME}

The Adhesome

Over the past several decades, surveys of the molecular constituents of cell-matrix adhesions-particularly integrin-mediated adhesions-indicate that they are composed of multiple molecules, which together participate in both the physical/structural and sensing/signaling activities of these adhesion structures. Based on their localization in FAs, interactions with other adhesion components, or involvement in the regulation of the organization and function of these sites, the entire collective of molecules associated with integrin adhesions was termed the integrin "adhesome" (http:// www.adhesome.org; Zaidel-Bar et al. 2007a). To date, the adhesome network (Zaidel-Bar and Geiger 2010) includes 180 components, based on immunolocalization studies, binding assays, RNA interference, and yeast two-hybrid analyses (Fig. 4). Particularly overwhelming is the large number of direct interactions ( $>700)$ reported among these various components, which can be divided into "scaffolding interactions" with direct binding between specific components, and "regulatory interactions" involving specific modification of one component by another component (e.g., phosphorylation and GTPase activation).

\section{Scaffolding within Adhesions}

The scaffolding interactions within cell adhesions that connect the many components to one another, and eventually link actin filaments to the cytoplasmic tails of integrin receptors, are indirect (Fig. 4). They involve two families of

Figure 3. (Continued) Podosomes consist of a core bundle of actin filaments (Act, green), oriented perpendicular to the plasma membrane; they are surrounded by a membrane-associated "adhesion ring" containing typical FA plaque molecules, including paxillin (red). In osteoclasts, podosomes accumulate along the cell edge, forming a belt-shaped "sealing zone" important for the process of bone resorption. The area in $(F)$ marked with the white rectangle is enlarged in $G$, highlighting the relationship between the actin core and the adhesion zone. Original images for this figure were provided by Tova Volberg, Ronen Zaidel-Bar, and Chen Luxenburg. 
B. Geiger and K.M. Yamada

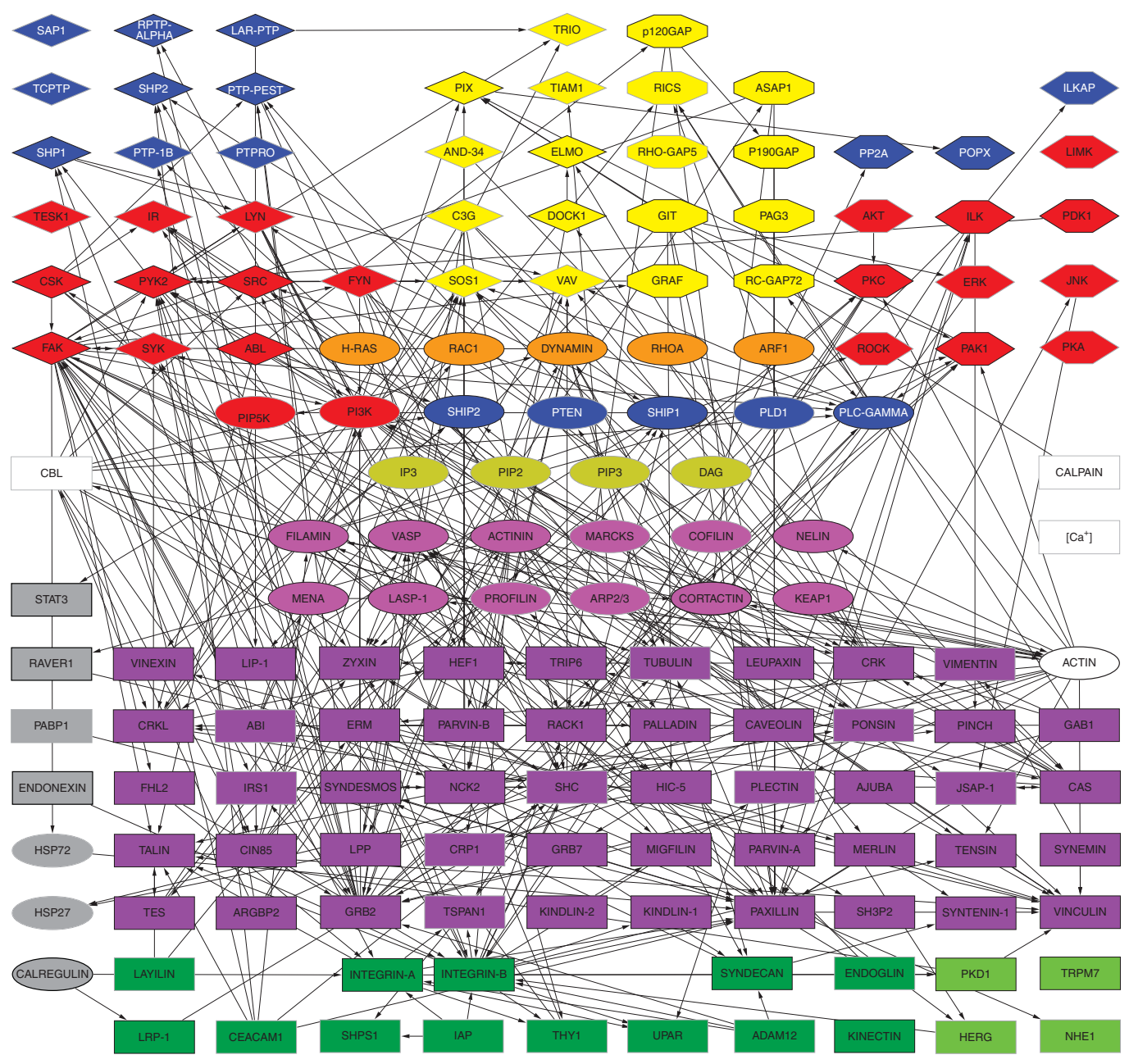

Figure 4. Scaffolding interactions of the integrin adhesome network (see http://www.adhesome.org). Adhesome components include membrane receptors (dark green rectangles), adaptor proteins (purple rectangles), actin-associated proteins (magenta ovals), tyrosine kinases (red diamonds) and phosphatases (blue diamonds), serine/threonine kinases (red elongated hexagons) and phosphatases (blue elongated hexagons), G-proteins (orange ovals), GEFs (yellow diamonds), and GAPs (yellow elongated octagons). This diagram was prepared by Ronen Zaidel-Bar, based on Zaidel-Bar et al. 2007a; Zaidel-Bar and Geiger 2010.

cytoplasmic molecules: "actin-associated molecules" and "adaptor proteins." The former proteins interact predominantly with actin and regulate its organization; only a few of these molecules (e.g., tensin, filamin, talin, plectin, and $\alpha$-actinin) are reported to interact directly with integrins. The adaptor molecules interact with these actin-associated components, with each other, and with integrin, forming a complex network of mechanical scaffolding links between actin and the membrane at the adhesion site (Geiger et al. 2001; Zaidel-Bar et al. 2007a).

\section{Regulation of Adhesions}

As the adhesome network grows in complexity and connectivity, it is increasingly apparent that to accommodate the need for both robustness and dynamic plasticity at the adhesion site, 


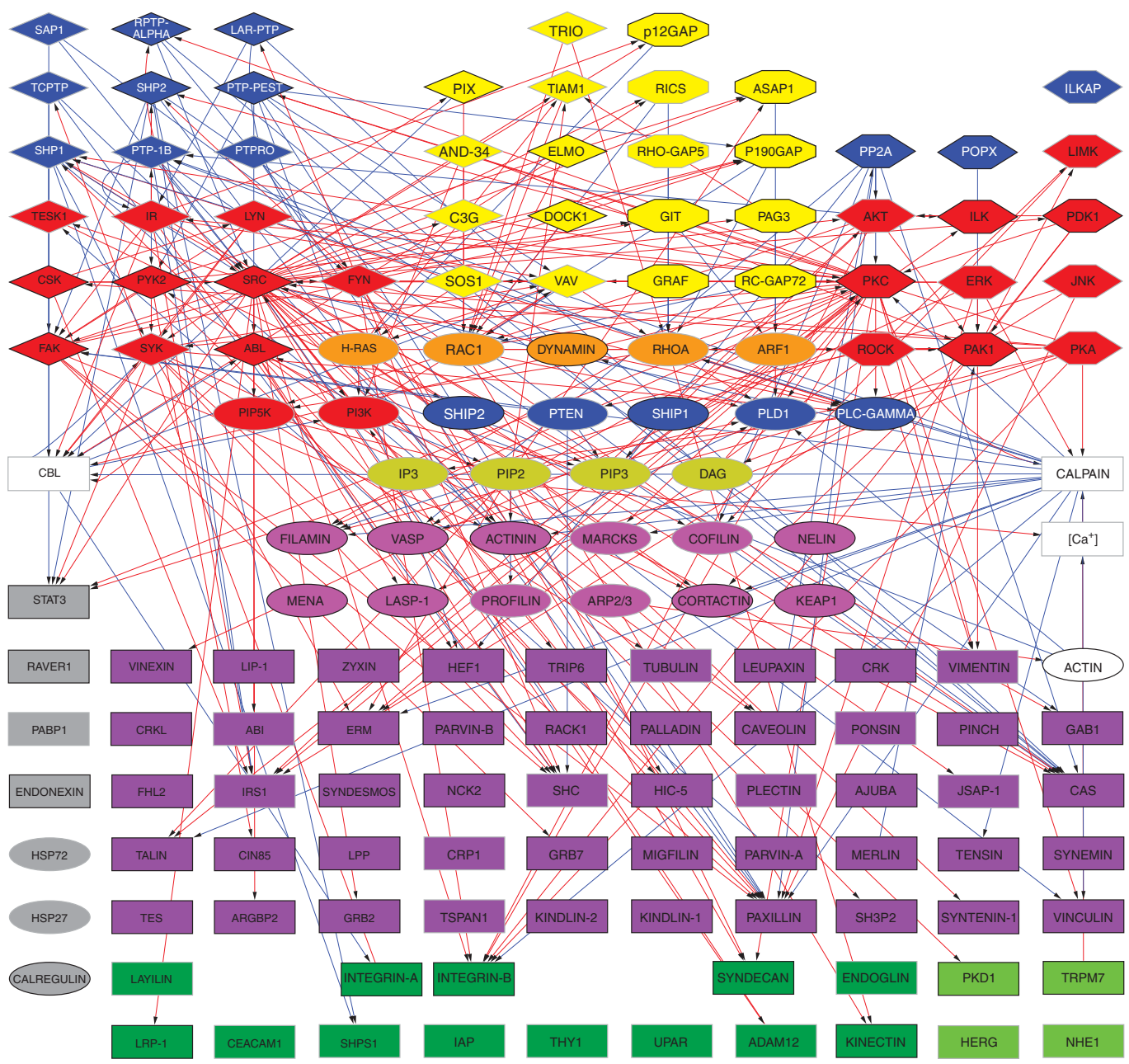

Figure 5. Regulatory (signaling) interactions of the integrin adhesome network; for details, see http://www.adhesome.org. Signaling components include kinases, phosphatases, G-proteins and their regulators, as well as proteases. Red arrows point to modifications such as phosphorylation and activation of Rho GTPases, and blue arrows indicate dephosphorylation, inactivation of Rho GTPases, and protein degradation. The classes of molecules are indicated in the legend to Figure 4. This diagram was prepared by Ronen Zaidel-Bar, based on Zaidel-Bar et al. 2007a; Zaidel-Bar and Geiger 2010.

many of these interactions need to be regulated. The signaling components of the adhesome are prime candidates for locally regulating adhesome connectivity, as well as for generating signals that globally affect cellular processes including cell division, migration, and differentiation. These signaling molecules include multiple tyrosine-specific and serine/threoninespecific protein kinases and phosphatases, Rho-family GTPases, and their regulators (GAPs and GEFs). Analysis of the nature of adhesome connectivity indicates that the signaling components bind to the adhesion sites via multiple docking sites present on the scaffolding network; they, in turn, modify this network and thus modulate its connectivity (Fig. 5).

Various types of posttranslational signaling modifications are known to directly affect the adhesome, though many others that regulate the functional interplay between scaffolding 
and signaling functions are likely to be found (Zaidel-Bar and Geiger 2010). For example, Crk, which has three major interaction domains (a Src homology 2 [SH2] domain and two SH3 domains), can interact with at least 16 different proteins, half of which can interact with the $\mathrm{SH} 3$ domains via their proline-rich sequences, and half interact with the $\mathrm{SH} 2$ domain via phosphorylated tyrosine residues. The $\mathrm{SH} 2$-domain partners are mostly other adaptor proteins, whereas the SH3-domain partners are mostly guanine-nucleotide exchange factors (GEFs) for GTPases. Because only some of the potential binding partners are expressed in any given cell type, the actual partner "switchboard" might be simpler than that derived from the adhesome database. However, many of these switches are real, and the choice of a particular interaction partner can affect the structure and function of the adhesion site.

Furthermore, different subpopulations of a given protein may interact with different binding partners in parallel, in the same cell, and possibly within the same adhesion site, compounding the complexity of the functional networking of adhesome components. Crk is an excellent example of a conformational switch. Switching in Crk and other molecules can be triggered by changes in temperature, $\mathrm{pH}$, or ion concentration; by the binding of another protein; or, as with Crk, by a posttranslational modification such as phosphorylation. Some adhesome proteins, such as vinculin, talin, focal adhesion kinase, Src, and TES (testis-derived transcript), can exist in either a closed (inactive) or open (active) conformation (Garvalov et al. 2003; Critchley 2004; Mitra and Schlaepfer 2006). In the closed conformation, which is usually maintained by specific interactions between the amino-terminal and carboxyterminal domains, important activity modules are concealed within the folded protein. The closed-to-open conformational switch involves a dramatic change in protein folding. Other conformational switches invoke smaller, but no less crucial, changes in amino acid positioning. For example, the extracellular domains of integrins are activated to bind ligands following specific interactions between their cytoplasmic tails and talin (Shimaoka et al. 2002; Campbell and Humphries 2011). In short, the adhesome interaction network is highly dynamic, and is regulated by the cellular signaling machinery.

\section{Functional Molecular Architecture of Adhesions}

The molecular architecture of integrin adhesions is currently under intense scrutiny. Initially, researchers used conventional electron microscopy (Fig. 6A) combined with various optical microscopy approaches, such as interference reflection microscopy, for visualizing the adhesion area (Fig. 6B) to characterize the internal structure of integrin adhesions. However, apart from detection of actin filaments and an amorphous electron-dense "plaque" associated with the membrane, no structural information was obtained (Abercrombie et al. 1970; Heaysman 1973; Dunn and Jones 1998; Weston 1982). Subsequent studies using different sample preparation and imaging strategies (e.g., whole-mount negative staining, wet cleavage, and high-resolution scanning electron microscopy) have provided little additional structural information, most likely because of sample dehydration. Whole-cell cryo-electron tomography (cryoET) and powerful superresolution optical microscopy constitute more recent approaches to understanding the molecular organization of FAs. Correlated microscopy, combining fluorescence microscopy with CryoET (Fig. 6C-F), shows that FAs are laminated structures, containing arrays of membrane-bound, doughnut-shaped particles $\sim 25 \mathrm{~nm}$ in diameter, spaced at $\sim 45 \mathrm{~nm}$ intervals, which are associated with a bundle of aligned actin filaments via short interconnecting filaments in close association with vinculin (Patla et al. 2010). Photoactivatable light microscopy (PALM) shows that in focal adhesions, vinculin displays a scattered pattern, similar to the distribution of the doughnut-shaped particles (Betzig et al. 2006). Further research using high-resolution microscopy with structural and molecular approaches will continue to clarify the molecular structure of the adhesion sites and the roles of the associated particles. 

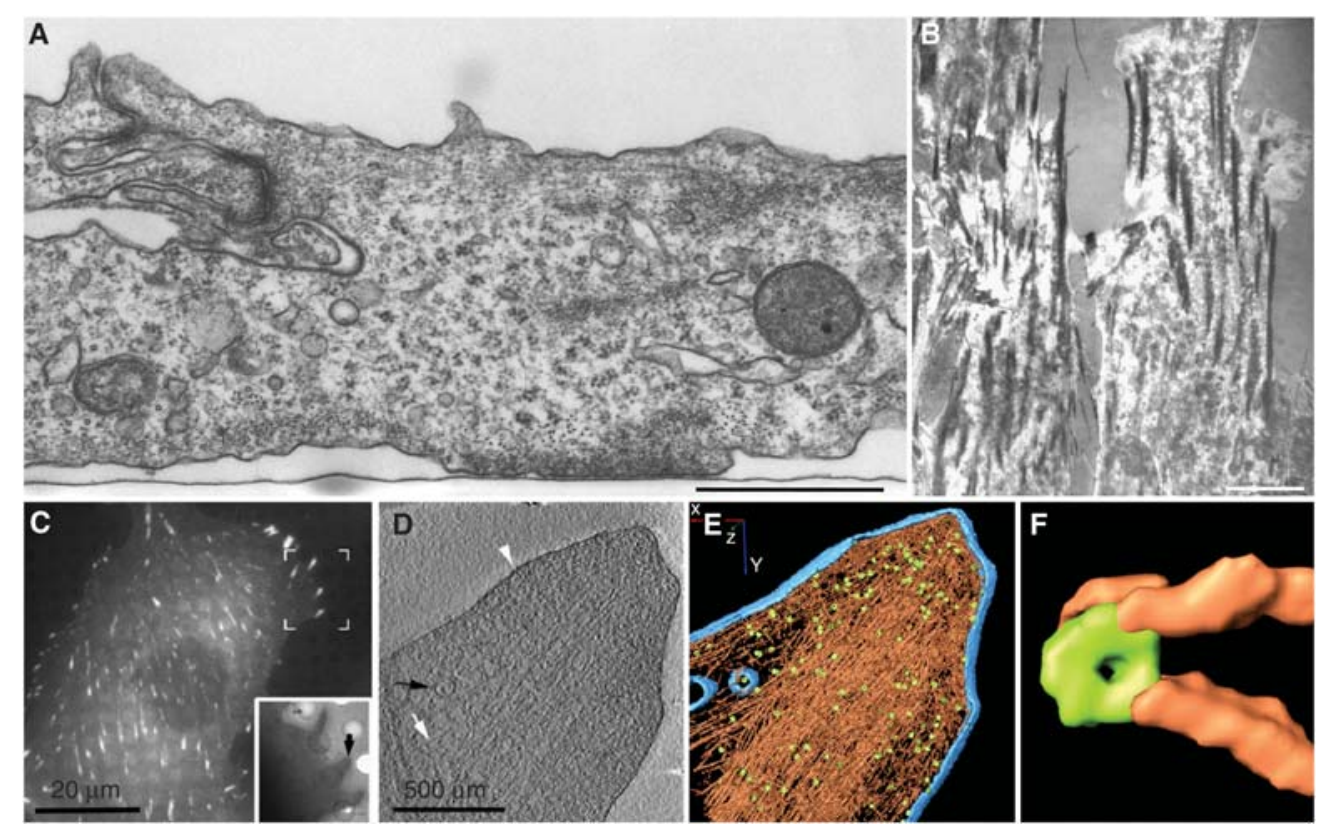

Figure 6. Different views of FA structure: $(A)$ Chicken lens cells were cultured on a flat surface, processed for transmission electron microscopy, and sectioned perpendicular to the plane of the substrate. The image reveals multiple cytoskeletal filaments accumulating at the adhesion site. The apparent gap between the ventral cell membrane and the substrate (indicated by a "serum line") is approximately $10-15 \mathrm{~nm}$. Bar $=1 \mu \mathrm{m}$. Original image provided by Ilana Sabanay. (B) Interference-reflection microscopy (IRM) of cell-matrix adhesions. This image shows cell adhesions of primary human fibroblasts, in which FAs appear dark gray or black, and the less tightly adhering "close contacts" are light gray. Bar $=10 \mu \mathrm{m}$. (Image adapted from Akiyama et al. 1989 and reprinted with permission from The Rockefeller University Press (C) 1989.) (C-F) Correlated microscopy, combining fluorescence microscopy $(C)$ of FAs in fibroblasts expressing fluorescent paxillin to identify adhesion sites, and cryo-electron tomography $(D-F)$. The inset in $(C)$ shows a low-power image of the region bracketed on the fluorescence image. (D) A 10-nm slice through a cryo-electron tomogram of the focal adhesion indicated in the inset in $(C)$, showing aligned actin filaments (white arrow), vesicle (black arrow), and the plasma membrane (white arrowhead). (E) Surface-rendering view of the focal adhesion site as seen from the direction of the substrate toward the cell. Actin is depicted in brown and membranes in blue; a large number of uniformly oriented particles, probably adhesionrelated and depicted in green, are located at the interface between the cytoskeletal bundle and the membrane. No scale bar is shown in $E$, as it is a "rendered" version of $D$; the diameter of the enlarged "doughnut" shown in panel $F$ is noted. $(F)$ An enlarged view of an individual particle (diameter $=25 \mathrm{~nm}$ ), and the associated filaments. Panels $C-F$ are based on data from Patla et al. 2010.

\section{ASSEMBLY AND REMODELING OF INTEGRIN ADHESIONS}

The various forms of integrin-based adhesions shown in Figure 3 are dynamic structures that can undergo maturation or interconversion.

\section{Early Adhesions and the Molecular Clutch}

The earliest integrin-containing structures detectable by light microscopy are the "focal complexes" or "nascent adhesions" (Nobes and Hall 1995; Geiger et al. 2001; Alexandrova et al. 2008; Choi et al. 2008) formed close to the leading edge of migrating cells. In this region of the cell, one can distinguish between the lamellipodium - a ribbon-like, flat protrusion located at the periphery of a moving or spreading cell, containing a network of actin filamentsand the lamella - a flat, broad, sheetlike cellular extension that is internal (medial) to lamellipodia. A fan-shaped lamella is a prominent feature that characterizes the leading edge of a cell that 
is undergoing locomotion on a flat surface. Actin networks that contain myosin IIA are the principal structures in lamellae. These early nascent adhesions and focal complexes are roughly $100 \mathrm{~nm}$ in diameter and positioned at the interface between the lamellipodium and the matrix; they are composed of only a few hundred protein molecules, including integrins, talin, and paxillin (Zaidel-Bar et al. 2003; Ponti et al. 2004; Giannone et al. 2007; Alexandrova et al. 2008; Choi et al. 2008). Within the lamelliopodium, actin polymerizes and flows centripetally at a rate of a few micrometers per minute (Ponti et al. 2004; Vallotton et al. 2004; Alexandrova et al. 2008), rubbing against these newly formed adhesion complexes, and apparently reinforcing integrin-cytoskeleton bonds. In particular, the binding of vinculin to talin triggers the clustering of activated integrins (Humphries et al. 2007) and, through the vinculin tail, their association with actin, thereby strengthening the actin-integrin link (Galbraith et al. 2002). These forces appear to drive the growth of the nascent adhesions into larger focal complexes, a process that can be blocked by low doses of cytochalasin D to inhibit the centripetal actin flow (Alexandrova et al. 2008; Choi et al. 2008). This system is thought to function as a "molecular clutch" to mediate cell migration by linking integrins and adhesion scaffolding molecules to the moving actin cytoskeleton (Huttenlocher and Horwitz 2011).

At the lamellipodial-lamellar interfaceusually located $\sim 2-4 \mu \mathrm{m}$ from the leading edge of the cell—the density of the actin filament network is substantially lower, and its architecture and protein composition are altered: in particular, Arp2/3 complexes are absent, whereas tropomyosin and myosin II are prominent (Ponti et al. 2004; Vallotton et al. 2004). The actin network in the lamella continues to flow centripetally, but at a lower speed than in the lamellipodium. Further growth of the young adhesion, still in the lamellipodial domain, depends not only on continued actin polymerization, but also on myosin II-driven contraction of the lamellipodium (Giannone et al. 2007).
Role of Force in the Development of Focal Adhesions

The transformation of focal complexes at the cell edge into stress fiber-bound focal adhesions is associated with changes in protein composition (e.g., the recruitment of zyxin), tyrosine phosphorylation (e.g., of paxillin), and dynamics (e.g., enhanced exchange rate) (Ballestrem et al. 2001; Cluzel et al. 2005; Ballestrem et al. 2006; Zaidel-Bar et al. 2007b; Zamir et al. 2008). This transition appears to occur at the boundary between the lamellipodium and the lamella (Ponti et al. 2004; Alexandrova et al. 2008; Choi et al. 2008).

As the lamellipodium and lamella advance during cell migration, the growing adhesions remain attached to the substrate and undergo a maturation process characterized by an increase in their length and total area, as well as association with the termini of actin stress fibers. This association with the contractile actomyosin machinery is critical for the growth, maintenance, and stability of these adhesions. Traction force microscopy indicates that the cell is pulling on the matrix at these adhesion sites, producing a local stress of $\sim 5 \mathrm{nN} / \mu \mathrm{m}^{2}$ (Balaban et al. 2001). If this force is increased (e.g., by direct mechanical probing, shear flow, or stretching of the substratum), the attached adhesion grows; conversely, relaxation of tension (e.g., by inhibitors of actomyosin or Rhokinase) leads to its dissociation. The actual forces at individual cell adhesions can be measured using different forms of force traction microscopy, as well as with force biosensors using fluorescence detection methods (Grashoff et al. 2010).

\section{Fibrillar Adhesions}

An additional step in the maturation of integrin adhesions, particularly in fibroblasts adhering to a fibronectin matrix, is the formation of "fibrillar adhesions" (Hynes and Destree 1978; Chen and Singer 1982; Chen et al. 1985; Zamir et al. 2000). These elongated matrix contacts are particularly prominent in central regions of cultured fibroblasts, and their formation is 
associated with fibronectin fibrillogenesis; the $\alpha 5 \beta 1$ integrin, along with tensin, appear to translocate away centripetally from focal adhesions, potentially providing forces that promote the formation of fibronectin fibrils (Pankov et al. 2000; Zamir et al. 2000; Baharloo et al. 2005). Similar to the formation of focal complexes and focal adhesions, matrix reorganization and formation of fibrillar adhesions are force-dependent processes (Zhong et al. 1998). These functions of local force highlight the mechanosensitive nature of integrin adhesions, from the earliest to the most mature.

\section{Adhesion Dynamics}

Adhesion dynamics are particularly important in cell migration (Huttenlocher and Horwitz 2011). There appear to be multiple mechanisms underlying the molecular dynamics within cell adhesions. The association of signaling molecules can be relatively transient in newly formed, integrin-based adhesions, whereas scaffolding molecules are more stable in their association, even if dynamic at a single-molecule level according to FRAP analyses (Miyamoto et al. 1996; Wolfenson et al. 2009b). Microtubules play active roles in regulating focal adhesion dynamics (Rinnerthaler et al. 1988; Small and Kaverina 2003). Microtubules are thought to target focal adhesions and to destabilize them, for example, potentially by locally releasing tension (Broussard et al. 2008). Additional mechanisms of turnover or removal of adhesion components include cleavage by the enzyme calpain (Zhong et al. 1998). Analyses of the mechanisms and regulation of adhesion dynamics will continue to be a fruitful area of research for many years to come (Huttenlocher and Horwitz 2011).

\section{ECM SENSING VIA INTEGRIN ADHESIONS}

Integrin adhesions have dual physiological functions-a physical, structural role that is critical for tissue and organ morphogenesis, and a sensing and signaling role whereby integrin-mediated interactions with the ECM activate cascades of signaling events. These
Functional Architecture of Matrix Adhesions

signals act both locally and globally, regulating local molecular interactions within the adhesion site and modulating its scaffolding activity, as well as affecting overall cellular physiology, including cell proliferation, transcriptional activity, migration, and survival.

The mechanisms underlying adhesionmediated signaling remain to be fully elucidated. Unlike the signaling events initiated by receptor tyrosine kinases that involve ligandinduced activation of receptor-mediated phosphorylation of diverse cellular targets (Alberts et al. 2008), adhesion-mediated signaling is believed to involve the adhesion-dependent clustering of adhesome-associated signaling molecules and their downstream substrates, thus initiating the signaling process (Miyamoto et al. 1995; Schwartz et al. 1995; Katz et al. 2002; Zaidel-Bar and Geiger 2010). A remarkable feature of cell adhesions is the large size of their cytoplasmic scaffold, which enables extensive cross talk between the localized signaling molecules and their diverse targets, resulting in cascading activation of multiple signal transduction pathways. Furthermore, these resident signaling molecules can also modify and modulate the scaffold, itself, to which the molecules are bound, thereby affecting the scaffold's structure and signaling activities. The signaling cascades initiated or modulated by integrins include nearly all well-known signal transduction pathways, including signaling through focal adhesion kinase (FAK), various Src family kinases, MAP kinases, PKCs, and phosphatidylinositol lipids (Clark and Brugge 1995; Schwartz et al. 1995; Giancotti and Ruoslahti 1999; Hynes 2002; Schwartz and Ginsberg 2002; Berrier and Yamada 2007; Abram and Lowell 2009; Harburger and Calderwood 2009; Zaidel-Bar and Geiger 2010).

Integrins, ECM molecules, and growth factors function cooperatively to integrate extracellular biochemical and physical inputs in signaling pathways that regulate a host of cellular functions including cell survival, proliferation, and differentiation (ffrench-Constant and Colognato 2004; Hynes 2009; Streuli and Akhtar 2009). Although the specific mechanisms that initiate integrin signaling are still 
being explored, two mechanisms in integrinbased adhesions are (1) the targeting of signaling molecules by integrins to the plasma membrane and (2) the aggregation of kinases and their substrates as cell adhesions form and organize. For example, simple experimental targeting of certain proteins such as FAK or Rac1 to the plasma membrane can stimulate their phosphorylation or activity (Chan et al. 1994; Chao et al. 2010). Moreover, mimicking the aggregating effects of integrin clustering by direct experimental clustering of membrane-anchored FAK can trigger downstream MAP kinase activity (Katz et al. 2002), similar to the well-known mechanism of signaling activation by aggregation of receptor tyrosine kinases after they bind growth factors (Alberts et al. 2008). These integrin signaling processes are accompanied by reorganization of cytoskeletal components at cell adhesions, including the formation of actin stress fibers. These integrin-cytoskeletal processes are coordinated by complex signaling cross talk involving FAK, Src family kinases, and various Rho family GTPases and their regulators (Dubash et al. 2009; Huveneers and Danen 2009).

\section{Chemical Sensing of the Extracellular Matrix and Signaling}

What types of matrix information are sensed by integrin adhesions to generate downstream signaling? The two major categories are chemical and physical cues. Cells sense the chemical properties of the matrix environment, particularly adhesive (e.g., fibronectin or vitronectin) and associated signaling molecules (e.g., heparin-binding EGF or fibroblast growth factors) encountered at the cell surface. As shown in Figure 2, interactions with different matrices via distinct receptors can indeed trigger distinct cellular responses. In addition, cells have extensive abilities to sense the physical state of the matrix, including its stiffness, topography, and ligand spacing.

Chemical sensing of the extracellular matrix microenvironment at cell adhesions involves a wide variety of receptors, which include integrin receptors for specific matrix molecules, nonintegrin matrix protein receptors such as CD44, proteoglycans such as syndecan- 4 , and receptors for growth factors and cytokines (Hay 1991; Alberts et al. 2008; Sarrazin et al. 2011; Sheppard and Munger 2011). These various receptors can function additively, synergistically, or antagonistically. Integrins can have specificity for a particular class of ECM molecule such as collagen or laminin (Hynes 2011). They can function together, or in cooperation with, molecules such as syndecans to promote the formation of adhesions; for example, certain cells require both integrin and syndecan- 4 function to form focal adhesions (Saoncella et al. 1999; Mostafavi-Pour et al. 2003). Integrins can also cross-inhibit the adhesive function of another integrin, in a process termed integrin cross talk, or transdominant inhibition (Blystone et al. 1994; Diaz-Gonzalez et al. 1996; Blystone et al. 1999; Gonzalez et al. 2010).

Integrins and growth factor receptors are present together in cell adhesions, and a number of collaborative interactions occur between integrins and growth factor receptors, with adhesions functioning as cell signaling centers (Schwartz et al. 1995; Miyamoto et al. 1996). Because of the extraordinary complexity of the adhesome (Figs. 4 and 5), innumerable cross talk interactions are likely between the many signaling and scaffolding interactions in cell adhesions. These interactions will continue to be elucidated by high-throughput analyses of cell adhesions and adhesion-dependent processes such as cell migration (Simpson et al. 2008; Winograd-Katz et al. 2009). For example, proteomics analysis of cell adhesions dependent on different integrins identify both shared and distinctive components with interesting potential functions; in one case, intersections between integrin, Rac, and Arf signaling networks were identified (Humphries et al. 2009).

\section{Physical Sensing of the Extracellular Matrix}

In addition to chemical sensing, cells can be exquisitely sensitive to differences in the physical state of the matrix, such as density, spacing, rigidity, and orientation. The mechanisms of adhesion-mediated sensing of the physical 
properties of the matrix are still under intensive investigation. It is known that the assembly of focal adhesions and induction of actin organization require certain threshold densities of adhesion ligands. As analyzed using precisely nano-patterned adhesive surfaces, the assembly of focal adhesions requires a ligand spacing of no more than $\sim 60-140 \mathrm{~nm}$ (Massia and Hubbell 1991; Cavalcanti-Adam et al. 2007; Geiger et al. 2009). Moreover, major differences are found between adhesion sites formed on compliant surfaces (sub-kPa to a few $\mathrm{kPa}$ ), compared with those formed on rigid surfaces (hundreds of $\mathrm{kPa}$ to a few $\mathrm{mPa}$ ) (Discher et al. 2005; Discher et al. 2009). Matrix geometry and topography are additional surface features that are known to play a role in guiding the formation of matrix adhesions (Cukierman et al. 2001; Geiger et al. 2001; Baharloo et al. 2005; Grossner-Schreiber et al. 2006), regulating their dynamic properties (Geblinger et al. 2010), and modulating their signaling activity.

It is interesting to note that this "multisensing" property of living cells for chemical and physical information implies that beyond the local sensing of individual matrix features, integrin adhesions are capable of integrating complex information (multiple physical, mechanical, and biochemical cell surface inputs) and developing a coherent, integrated response. Understanding the workings of this integration mechanism is a major challenge in the cell adhesion field.

\section{A TWO-WAY DIALOGUE BETWEEN CELLS AND THE EXTRACELLULAR MATRIX}

The matrix is synthesized and organized by cells but, as discussed above, the matrix itself can reciprocally regulate cell behavior. The assembly of fibronectin-based or collagen-based matrices, compared to basement membranes (for examples, see Schwarzbauer and DeSimone 2011; Yurchenco 2010), differs in terms of molecular components and cellular structures (e.g., fibrillar adhesions associated with fibronectin, versus fibripositors with collagen [Canty et al. 2004], versus other assembly mechanisms for basement membranes). These processes share, however, the principle features of specific matrix molecule binding and spatial organization of the ECM by integrins or other matrix receptors. Similarly, reorganization of matrix molecules in wounds, and the transition from a provisional matrix containing fibrin and fibronectin to dense collagen in scars, also involves integrins and specific cell types (see Clark 1996; Watt and Fujiwara 2011). Cell-type specificity of adhesion and biosynthesis-for example, fibroblasts in collagenous matrices and epithelial cells on basement membranescan help to maintain overall tissue organization and differentiation.

A further major role of the ECM, however, is its function as a reservoir for growth factors, cytokines, and other extracellular factors. For example, both the glycoprotein and glycosaminoglycan (especially heparan sulfate) components of the matrix can enhance signaling, adhesive functioning, and remodeling (Vaday et al. 2001; Hynes 2009).

The bidirectional relationships of cells and the ECM are particularly clear in the regulation of cell migration directionality (Petrie et al. 2009; Huttenlocher and Horwitz 2011). Physical properties of the matrix conveyed through cell adhesions include sensing rigidity and orientation of fibrils. Stiffer matrices evoke larger focal adhesions and increased intracellular contractility, and cells will move toward areas of greater substrate stiffness, in a process termed durotaxis (Pelham and Wang 1997). In addition, however, cells can reorganize a random meshwork of collagen fibrils into oriented fibrils (Provenzano et al. 2006), which in turn promotes their migration along the reorganized fibrils. This propensity to migrate along oriented patterns such as fibrils or grooves is known as "contact guidance," which strongly promotes integrin-dependent migration along linearly patterned ECM and can involve unusually elongated cell adhesions (Cukierman et al. 2001; Provenzano et al. 2006; Doyle et al. 2009). Particularly dramatic switches in adhesion-from cell-cell adhesion to enhanced cell-ECM adhesion-can occur in epithelial-mesenchymal transitions (EMT) or weaker variants of this process, which appear 
to play important roles in embryonic cell migration, organ development, and tumor cell invasion (Kalluri and Weinberg 2009; Thiery et al. 2009; Onodera et al. 2010).

\section{CONCLUSIONS: INTEGRIN ADHESIONS AS "INTERACTIVE INFORMATION INTERFACES" BETWEEN CELLS AND THEIR ENVIRONMENT}

Integrins and other cell surface receptors provide external links to the ECM, but their functions at the cell-ECM interface require the participation of a multiprotein complex of adhesome components consisting of both scaffolding and signaling molecules. In a way, the adhesion interfaces can be envisioned as two intertwined multiprotein scaffolds (the extracellular ECM and the adhesome network) that reorganize each other under the control of the adhesome signaling machinery. This "design principle" is schematically illustrated in Figure 1 of this article, and the underlying molecular mechanisms are outlined in this article as well. It provides an interactive interface for the bidirectional exchange of information and functional alterations at the cell surface.

The temporal functional plasticity of adhesion sites can be envisioned as the following sequence of events: (1) Initial encounter between the cell membrane and the ECM; (2) Integrative assessment of the ECM by the cellular adhesion machinery; (3) Local assembly and activation of the adhesion-associated signaling system; (4) Modulation of the adhesome scaffolding network and the associated cytoskeleton, resulting in: (5a) Mechanical reorganization of the ECM (which may trigger another scaffolding-signaling cycle), and (5b) Activation of global adhesion-mediated signaling that can regulate cell proliferation, migration, survival, and differentiation.

An ongoing challenge in the field involves testing this model, substantiating it, and determining the role of specific molecules in the regulation and integration of the complex functions of cell adhesions. There are likely to be numerous variations on the theme of receptor-ECM binding, receptor-ligand aggregation, adhesion assembly, and maturation, along with a changing cast of molecular constituents, depending on the cell type and the biological process or function involved. The successful integration of cell adhesion functions is essential for understanding normal development and ongoing tissue function, as well as mutations in the various adhesome components that can result in diseases ranging from fetal death, to skin blistering, to bleeding disorders (e.g., see Wickstrom et al. 2010). Besides such genetic diseases, altered cell adhesion might contribute to diseases such as cancer, skin disorders, and fibrosis (see Watt and Fujiwara 2011).

Major opportunities in the field will include identifying the specific set of adhesome structure-function relationships relevant to a particular function, such as cell migration, invasion, or disease, and then understanding their regulation by both intracellular and extracellular processes. This level of understanding will require complex systems-level approaches and computational modeling, which include not only the molecular components and their signal transduction relationships, but also a thorough knowledge of mechanotransduction principles and the bidirectional roles of local and global forces acting on cell adhesions. These conceptual and experimental challenges should provide fruitful opportunities for research in this area in the near future, and for many years to come.

\section{ACKNOWLEDGMENTS}

BG is the incumbent of the Erwin Neter Professorial Chair in Cell and Tumor Biology. Studies addressing the adhesome network and mechanosensitivity were supported by the National Institute of General Medical Sciences grant for the Cell Migration Consortium (NIH grant no. U54GM64346); the Nanotechnology Center for Mechanics in Regenerative Medicine (part of the NIH Nanomedicine Development Center Network; NIH grant no. PN2 EY016586), the Mario Negri Institute for Pharmacological Research - Weizmann Institute of Science Exchange Program, and the Israel Science Foundation. KMY is supported by the Intramural 
Research Program of the National Institute of Dental and Craniofacial Research, National Institutes of Health. The authors would like to express their gratitude to Chen Luxenburg, Tova Volberg, Ronen Zaidel-Bar, and Baruch Zimerman for providing data presented in this article. The authors also wish to thank Barbara Morgenstern for excellent editorial assistance.

\section{REFERENCES}

Abercrombie M, Heaysman JE, Pegrum SM. 1970. The locomotion of fibroblasts in culture. I. Movements of the leading edge. Exp Cell Res 59: 393-398.

Abram CL, Lowell CA. 2009. The ins and outs of leukocyte integrin signaling. Annu Rev Immunol 27: 339-362.

Akiyama SK, Yamada SS, Chen WT, Yamada KM. 1989. Analysis of fibronectin receptor function with monoclonal antibodies: Roles in cell adhesion, migration, matrix assembly, and cytoskeletal organization. J Cell Biol 109: 863-875.

Alberts B, Johnson A, Lewis J, Raff M, Roberts K, Walter P. 2008. Molecular biology of the cell. Garland Science, New York.

Alexandrova AY, Arnold K, Schaub S, Vasiliev JM, Meister JJ, Bershadsky AD, Verkhovsky AB. 2008. Comparative dynamics of retrograde actin flow and focal adhesions: Formation of nascent adhesions triggers transition from fast to slow flow. PLoS ONE 3: e3234.

Amatangelo MD, Bassi DE, Klein-Szanto AJ, Cukierman E. 2005. Stroma-derived three-dimensional matrices are necessary and sufficient to promote desmoplastic differentiation of normal fibroblasts. Am J Pathol 167: 475-488.

Artym VV, Matsumoto K, Mueller SC, Yamada KM. 2011. Dynamic membrane remodeling at invadopodia differentiates invadopodia from podosomes. Eur J Cell Biol 90: 172-180.

Baharloo B, Textor M, Brunette DM. 2005. Substratum roughness alters the growth, area, and focal adhesions of epithelial cells, and their proximity to titanium surfaces. J Biomed Mater Res A 74: 12-22.

Balaban NQ, Schwarz US, Riveline D, Goichberg P, Tzur G, Sabanay I, Mahalu D, Safran S, Bershadsky A, Addadi L, et al. 2001. Force and focal adhesion assembly: A close relationship studied using elastic micropatterned substrates. Nat Cell Biol 3: 466-472.

Ballestrem C, Erez N, Kirchner J, Kam Z, Bershadsky A, Geiger B. 2006. Molecular mapping of tyrosine-phosphorylated proteins in focal adhesions using fluorescence resonance energy transfer. J Cell Sci 119: 866-875.

Ballestrem C, Hinz B, Imhof BA, Wehrle-Haller B. 2001. Marching at the front and dragging behind: Differential $\alpha \mathrm{V} \beta 3$-integrin turnover regulates focal adhesion behavior. J Cell Biol 155: 1319-1332.

Beacham DA, Cukierman E. 2005. Stromagenesis: The changing face of fibroblastic microenvironments during tumor progression. Semin Cancer Biol 15: 329-341.
Berrier AL, Yamada KM. 2007. Cell-matrix adhesion. J Cell Physiol 213: 565-573.

Betzig E, Patterson GH, Sougrat R, Lindwasser OW, Olenych S, Bonifacino JS, Davidson MW, Lippincott-Schwartz J, Hess HF. 2006. Imaging intracellular fluorescent proteins at nanometer resolution. Science 313: 1642-1645.

Block MR, Badowski C, Millon-Fremillon A, Bouvard D, Bouin AP, Faurobert E, Gerber-Scokaert D, Planus E, Albiges-Rizo C. 2008. Podosome-type adhesions and focal adhesions, so alike yet so different. Eur J Cell Biol 87: 491-506.

Blystone SD, Graham IL, Lindberg FP, Brown EJ. 1994. Integrin $\alpha v \beta 3$ differentially regulates adhesive and phagocytic functions of the fibronectin receptor $\alpha 5 \beta 1$. J Cell Biol 127: 1129-1137.

Blystone SD, Slater SE, Williams MP, Crow MT, Brown EJ. 1999. A molecular mechanism of integrin crosstalk: avß3 suppression of calcium/calmodulin-dependent protein kinase II regulates $\alpha 5 \beta 1$ function. J Cell Biol 145: 889-897.

Broussard JA, Webb DJ, Kaverina I. 2008. Asymmetric focal adhesion disassembly in motile cells. Curr Opin Cell Biol 20: $85-90$.

Butcher DT, Alliston T, Weaver VM. 2009. A tense situation: Forcing tumour progression. Nat Rev Cancer 9: 108-122.

Caldieri G, Ayala I, Attanasio F, Buccione R. 2009. Cell and molecular biology of invadopodia. Int Rev Cell Mol Biol 275: $1-34$.

Campbell ID, Humphries MJ. 2011. Integrin structure, activation, and interactions. Cold Spring Harb Perspect Biol doi:10.1101/cshperspect.a004994.

Canty EG, Lu Y, Meadows RS, Shaw MK, Holmes DF, Kadler KE. 2004. Coalignment of plasma membrane channels and protrusions (fibripositors) specifies the parallelism of tendon. J Cell Biol 165: 553-563.

Cavalcanti-Adam EA, Volberg T, Micoulet A, Kessler H, Geiger B, Spatz JP. 2007. Cell spreading and focal adhesion dynamics are regulated by spacing of integrin ligands. Biophys J 92: 2964-2974.

Chan PY, Kanner SB, Whitney G, Aruffo A. 1994. A transmembrane-anchored chimeric focal adhesion kinase is constitutively activated and phosphorylated at tyrosine residues identical to pp125FAK. J Biol Chem 269: 20567-20574.

Chao WT, Daquinag AC, Ashcroft F, Kunz J. 2010. Type I PIPK- $\alpha$ regulates directed cell migration by modulating Rac1 plasma membrane targeting and activation. J Cell Biol 190: 247-262.

Chen WT, Singer SJ. 1982. Immunoelectron microscopic studies of the sites of cell-substratum and cell-cell contacts in cultured fibroblasts. J Cell Biol 95: 205-222.

Chen WT, Hasegawa E, Hasegawa T, Weinstock C, Yamada KM. 1985. Development of cell surface linkage complexes in cultured fibroblasts. J Cell Biol 100: 1103-1114.

Choi CK, Vicente-Manzanares M, Zareno J, Whitmore LA, Mogilner A, Horwitz AR. 2008. Actin and $\alpha$-actinin orchestrate the assembly and maturation of nascent adhesions in a myosin II motor-independent manner. Nat Cell Biol 10: 1039-1050.

Cichy J, Pure E. 2003. The liberation of CD44. J Cell Biol 161: 839-843. 
B. Geiger and K.M. Yamada

Clark EA, Brugge JS. 1995. Integrins and signal transduction pathways: The road taken. Science 268: 233-239.

Clark RAF, ed. 1996. The molecular and cellular biology of wound repair. Plenum Press, New York.

Cluzel C, Saltel F, Lussi J, Paulhe F, Imhof BA, Wehrle-Haller B. 2005. The mechanisms and dynamics of $(\alpha) v(\beta) 3$ integrin clustering in living cells. J Cell Biol 171:383-392.

Cohen DM, Kutscher B, Chen H, Murphy DB, Craig SW. 2006. A conformational switch in vinculin drives formation and dynamics of a talin-vinculin complex at focal adhesions. J Biol Chem 281: 16006-16015.

Couchman JR, Rees DA. 1979. The behaviour of fibroblasts migrating from chick heart explants: Changes in adhesion, locomotion and growth, and in the distribution of actomyosin and fibronectin. J Cell Sci 39: 149-165.

Critchley DR. 2004. Cytoskeletal proteins talin and vinculin in integrin-mediated adhesion. Biochem Soc Trans 32: 831-836.

Cukierman E, Pankov R, Stevens DR, Yamada KM. 2001. Taking cell-matrix adhesions to the third dimension. Science 294: 1708-1712.

Curtis A, Wilkinson C. 1997. Topographical control of cells. Biomaterials 18: 1573-1583.

Damsky CH, Knudsen KA, Bradley D, Buck CA, Horwitz AF 1985. Distribution of the cell substratum attachment (CSAT) antigen on myogenic and fibroblastic cells in culture. J Cell Biol 100: 1528-1539.

Davies PF, Robotewskyj A, Griem ML. 1994. Quantitative studies of endothelial cell adhesion. Directional remodeling of focal adhesion sites in response to flow forces. $J$ Clin Invest 93: 2031-2038.

Diaz-Gonzalez F, Forsyth J, Steiner B, Ginsberg MH. 1996. Trans-dominant inhibition of integrin function. $\mathrm{Mol}$ Biol Cell 7: 1939-1951.

Discher DE, Janmey P, Wang YL. 2005. Tissue cells feel and respond to the stiffness of their substrate. Science 310: 1139-1143.

Discher DE, Mooney DJ, Zandstra PW. 2009. Growth factors, matrices, and forces combine and control stem cells. Science 324: 1673-1677.

Doyle AD, Wang FW, Matsumoto K, Yamada KM. 2009. One-dimensional topography underlies threedimensional fibrillar cell migration. J Cell Biol 184: 481-490.

Dubash AD, Menold MM, Samson T, Boulter E, GarciaMata R, Doughman R, Burridge K. 2009. Chapter 1. Focal adhesions: New angles on an old structure. Int Rev Cell Mol Biol 277: 1-65.

Dunn G, Jones G. 1998. Michael Abercrombie: The pioneer ethologist of cells. Trends Cell Biol 8: 124-126.

Elsdale T, Bard J. 1972. Collagen substrata for studies on cell behavior. J Cell Biol 54: 626-637.

Engler AJ, Sweeney HL, Discher DE, Schwarzbauer JE. 2007. Extracellular matrix elasticity directs stem cell differentiation. J Musculoskelet Neuronal Interact 7: 335.

Estrada-Bernal A, Gatlin JC, Sunpaweravong S, Pfenninger KH. 2009. Dynamic adhesions and MARCKS in melanoma cells. J Cell Sci 122: 2300-2310.
ffrench-Constant C, Colognato H. 2004. Integrins: Versatile integrators of extracellular signals. Trends Cell Biol 14: 678-686.

Friedland JC, Lee MH, Boettiger D. 2009. Mechanically activated integrin switch controls $\alpha 5 \beta 1$ function. Science 323: $642-644$.

Galbraith CG, Yamada KM, Sheetz MP. 2002. The relationship between force and focal complex development. J Cell Biol 159: 695-705.

Garvalov BK, Higgins TE, Sutherland JD, Zettl M, Scaplehorn N, Kocher T, Piddini E, Griffiths G, Way M. 2003. The conformational state of Tes regulates its zyxin-dependent recruitment to focal adhesions. J Cell Biol 161: 33-39.

Geblinger D, Addadi L, Geiger B. 2010. Nano-topography sensing by osteoclasts. J Cell Sci 123: 1503-1510.

Geiger B, Bershadsky A, Pankov R, Yamada KM. 2001 Transmembrane crosstalk between the extracellular matrix and the cytoskeleton. Nat Rev Mol Cell Biol 2: 793-805.

Geiger B, Spatz JP, Bershadsky AD. 2009. Environmental sensing through focal adhesions. Nat Rev Mol Cell Biol 10: $21-33$.

Giancotti FG, Ruoslahti E. 1999. Integrin signaling. Science 285: 1028-1032.

Giannone G, Dubin-Thaler BJ, Rossier O, Cai Y, Chaga O, Jiang G, Beaver W, Dobereiner HG, Freund Y, Borisy G, et al. 2007. Lamellipodial actin mechanically links myosin activity with adhesion-site formation. Cell 128: 561-575.

Gimona M, Buccione R, Courtneidge SA, Linder S. 2008. Assembly and biological role of podosomes and invadopodia. Curr Opin Cell Biol 20: 235-241.

Girard PR, Nerem RM. 1995. Shear stress modulates endothelial cell morphology and F-actin organization through the regulation of focal adhesion-associated proteins. $J$ Cell Physiol 163: 179-193.

Gonzalez AM, Bhattacharya R, deHart GW, Jones JC. 2010. Transdominant regulation of integrin function: Mechanisms of crosstalk. Cell Signal 22: 578-583.

Gospodarowicz D, Delgado D, Vlodavsky I. 1980. Permissive effect of the extracellular matrix on cell proliferation in vitro. Proc Natl Acad Sci 77: 4094-4098.

Grashoff C, Hoffman BD, Brenner MD, Zhou R, Parsons M, Yang MT, McLean MA, Sligar SG, Chen CS, Ha T, et al. 2010. Measuring mechanical tension across vinculin reveals regulation of focal adhesion dynamics. Nature 466: $263-266$.

Grinnell F, Petroll WM. 2010. Cell motility and mechanics in three-dimensional collagen matrices. Annu Rev Cell Dev Biol 26: 335-361.

Grossner-Schreiber B, Herzog M, Hedderich J, Duck A, Hannig M, Griepentrog M. 2006. Focal adhesion contact formation by fibroblasts cultured on surface-modified dental implants: An in vitro study. Clin Oral Implants Res 17: 736-745.

Harburger DS, Calderwood DA. 2009. Integrin signalling at a glance. J Cell Sci 122: 159-163.

Hay ED, ed. 1991. Cell biology of extracellular matrix. Plenum Press, New York. 
Heaysman J. 1973. Early contacts between fibroblasts: An ultrastructural study. Exp Cell Res 78: 71-78.

Heino J, Huhtala M, Kapyla J, Johnson MS. 2009. Evolution of collagen-based adhesion systems. Int J Biochem Cell Biol 41: 341-348.

Huang C, Rajfur Z, Borchers C, Schaller MD, Jacobson K. 2003. JNK phosphorylates paxillin and regulates cell migration. Nature 424: 219-223.

Humphries JD, Byron A, Bass MD, Craig SE, Pinney JW, Knight D, Humphries MJ. 2009. Proteomic analysis of integrin-associated complexes identifies RCC2 as a dual regulator of Rac1 and Arf6. Sci Signal 2: ra51.

Humphries JD, Wang P, Streuli C, Geiger B, Humphries MJ, Ballestrem C. 2007. Vinculin controls focal adhesion formation by direct interactions with talin and actin. J Cell Biol 179: 1043-1057.

Huttenlocher A, Horwitz AR. Integrins in cell migration. Cold Spring Harb Perspect Biol doi:10.1101/ cshperspect.a005074.

Huveneers S, Danen EH. 2009. Adhesion signaling—crosstalk between integrins, Src and Rho. J Cell Sci 122: 1059-1069.

Hynes RO. 2011. Overview of the matrisome-ECM inventory. Cold Spring Harb Perspect Biol doi:10.1101/ cshperspect.a004903.

Hynes RO. 2002. Integrins: Bidirectional, allosteric signaling machines. Cell 110: 673-687.

Hynes RO. 2009. The extracellular matrix: Not just pretty fibrils. Science 326: 1216-1219.

Hynes RO, Destree AT. 1978. Relationships between fibronectin (LETS protein) and actin. Cell 15: 875-886.

Izzard CS, Lochner LR. 1976. Cell-to-substrate contacts in living fibroblasts: An interference reflexion study with an evaluation of the technique. J Cell Sci 21: 129-159.

Kalluri R, Weinberg RA. 2009. The basics of epithelialmesenchymal transition. J Clin Invest 119: 1420-1428.

Katz BZ, Miyamoto S, Teramoto H, Zohar M, Krylov D, Vinson C, Gutkind JS, Yamada KM. 2002. Direct transmembrane clustering and cytoplasmic dimerization of focal adhesion kinase initiates its tyrosine phosphorylation. Biochim Biophys Acta 1592: 141-152.

Katz BZ, Zamir E, Bershadsky A, Kam Z, Yamada KM, Geiger B. 2000. Physical state of the extracellular matrix regulates the structure and molecular composition of cell-matrix adhesions. Mol Biol Cell 11: 1047-1060.

Klein EA, Yin L, Kothapalli D, Castagnino P, Byfield FJ, Xu T, Levental I, Hawthorne E, Janmey PA, Assoian RK. 2009. Cell-cycle control by physiological matrix elasticity and in vivo tissue stiffening. Curr Biol 19: 1511-1518.

Levental KR, Yu H, Kass L, Lakins JN, Egeblad M, Erler JT, Fong SF, Csiszar K, Giaccia A, Weninger W, et al. 2009. Matrix crosslinking forces tumor progression by enhancing integrin signaling. Cell 139: 891-906.

Ley K, Kansas GS. 2004. Selectins in T-cell recruitment to non-lymphoid tissues and sites of inflammation. Nat Rev Immunol 4: 325-335.

Manevich-Mendelson E, Feigelson SW, Pasvolsky R, Aker M, Grabovsky V, Shulman Z, Kilic SS, Rosenthal-Allieri MA, Ben-Dor S, Mory A, et al. 2009. Loss of Kindlin-3 in LAD-III eliminates LFA-1 but not VLA-4 adhesiveness developed under shear flow conditions. Blood 114: 2344-2353.

Massia SP, Hubbell JA. 1991. An RGD spacing of $440 \mathrm{~nm}$ is sufficient for integrin $\alpha v \beta 3$-mediated fibroblast spreading and $140 \mathrm{~nm}$ for focal contact and stress fiber formation. J Cell Biol 114: 1089-1100.

Mitra SK, Schlaepfer DD. 2006. Integrin-regulated FAK-Src signaling in normal and cancer cells. Curr Opin Cell Biol 18: $516-523$.

Miyamoto S, Teramoto H, Coso OA, Gutkind JS, Burbelo PD, Akiyama SK, Yamada KM. 1995. Integrin function: Molecular hierarchies of cytoskeletal and signaling molecules. J Cell Biol 131: 791-805.

Miyamoto S, Teramoto H, Gutkind JS, Yamada KM. 1996. Integrins can collaborate with growth factors for phosphorylation of receptor tyrosine kinases and MAP kinase activation: Roles of integrin aggregation and occupancy of receptors. J Cell Biol 135: 1633-1642.

Mory A, Feigelson SW, Yarali N, Kilic SS, Bayhan GI, Gershoni-Baruch R, Etzioni A, Alon R. 2008. Kindlin-3: A new gene involved in the pathogenesis of LAD-III. Blood 112: 2591.

Mostafavi-Pour Z, Askari JA, Parkinson SJ, Parker PJ, Ng TT, Humphries MJ. 2003. Integrin-specific signaling pathways controlling focal adhesion formation and cell migration. J Cell Biol 161: 155-167.

Munger JS, Sheppard D. 2011. Cross talk among TGF signaling pathways, integrins, and the extracellular matrix. Cold Spring Harb Perspect Biol doi:10.1101/ cshperspect.a005017.

Nelson CM, Bissell MJ. 2006. Of extracellular matrix, scaffolds, and signaling: Tissue architecture regulates development, homeostasis, and cancer. Annu Rev Cell Dev Biol 22: 287-309.

Nobes CD, Hall A. 1995. Rho, rac, and cdc42 GTPases regulate the assembly of multimolecular focal complexes associated with actin stress fibers, lamellipodia, and filopodia. Cell 81: 53-62.

Onodera T, Sakai T, Hsu JC, Matsumoto K, Chiorini JA, Yamada KM. 2010. Btbd7 regulates epithelial cell dynamics and branching morphogenesis. Science 329: 562-565.

Pankov R, Cukierman E, Katz BZ, Matsumoto K, Lin DC, Lin S, Hahn C, Yamada KM. 2000. Integrin dynamics and matrix assembly: Tensin-dependent translocation of $\alpha(5) \beta(1)$ integrins promotes early fibronectin fibrillogenesis. J Cell Biol 148: 1075-1090.

Patla I, Volberg T, Elad N, Hiershfeld-Warneken V, Grashoff C, Fassler R, Spatz JP, Geiger B, Medalia O. 2010. Dissecting the molecular architecture of integrin adhesion sites by cryo-electron tomography. Nat Cell Biol 12: 909-915.

Pelham RJJr, Wang Y. 1997. Cell locomotion and focal adhesions are regulated by substrate flexibility. Proc Natl Acad Sci 94: 13661-13665.

Petrie RJ, Doyle AD, Yamada KM. 2009. Random versus directionally persistent cell migration. Nat Rev Mol Cell Biol 10: 538-549.

Poincloux R, Lizarraga F, Chavrier P. 2009. Matrix invasion by tumour cells: A focus on MT1-MMP trafficking to invadopodia. J Cell Sci 122: 3015-3024. 
B. Geiger and K.M. Yamada

Ponti A, Machacek M, Gupton SL, Waterman-Storer CM, Danuser G. 2004. Two distinct actin networks drive the protrusion of migrating cells. Science 305: 1782-1786.

Provenzano PP, Eliceiri KW, Campbell JM, Inman DR, White JG, Keely PJ. 2006. Collagen reorganization at the tumor-stromal interface facilitates local invasion. BMC Med 4: 38.

Pure E, Assoian RK. 2009. Rheostatic signaling by CD44 and hyaluronan. Cell Signal 21: 651-655.

Ricard-Blum S. 2011. The collagen family. Cold Spring Harb Perspect Biol doi:10.1101/cshperspect.a004978.

Rinnerthaler G, Geiger B, Small JV. 1988. Contact formation during fibroblast locomotion: Involvement of membrane ruffles and microtubules. J Cell Biol 106: 747-760.

Rottner K, Hall A, Small JV. 1999. Interplay between Rac and Rho in the control of substrate contact dynamics. Curr Biol 9: 640-648.

Saoncella S, Echtermeyer F, Denhez F, Nowlen JK, Mosher DF, Robinson SD, Hynes RO, Goetinck PF. 1999. Syndecan-4 signals cooperatively with integrins in a Rho-dependent manner in the assembly of focal adhesions and actin stress fibers. Proc Natl Acad Sci 96: 2805-2810.

Sarrazin S, Lamanna WC, Esko JD. 2011. Heparan sulfate protoglycans. Cold Spring Harb Perspect Biol doi:10.1101/cshperspect.a004952.

Schwartz MA. 2010. Integrins and extracellular matrix in mechanotransduction. Cold Spring Harb Perspect Biol 2010 2:a005066

Schwartz MA, Ginsberg MH. 2002. Networks and crosstalk: Integrin signalling spreads. Nat Cell Biol 4: E65-E68.

Schwartz MA, Schaller MD, Ginsberg MH. 1995. Integrins: Emerging paradigms of signal transduction. Annu Rev Cell Dev Biol 11: 549-599.

Schwarzbauer JE, DeSimone DW. 2011. Fibronectins, their fibrillogenesis, and in vivo functions. Cold Spring Harb Perspect Biol doi:10.1101/cshperspect.a005041.

Shimaoka M, Takagi J, Springer TA. 2002. Conformational regulation of integrin structure and function. Annu Rev Biophys Biomol Struct 31: 485-516.

Simpson KJ, Selfors LM, Bui J, Reynolds A, Leake D, Khvorova A, Brugge JS. 2008. Identification of genes that regulate epithelial cell migration using an siRNA screening approach. Nat Cell Biol 10: 1027-1038.

Singer II. 1979. The fibronexus: A transmembrane association of fibronectin-containing fibers and bundles of $5 \mathrm{~nm}$ microfilaments in hamster and human fibroblasts. Cell 16: 675-685.

Small JV, Kaverina I. 2003. Microtubules meet substrate adhesions to arrange cell polarity. Curr Opin Cell Biol 15: $40-47$.

Small JV, Furst DO, De Mey J. 1986. Localization of filamin in smooth muscle. J Cell Biol 102: 210-220.

Spinardi L, Marchisio PC. 2006. Podosomes as smart regulators of cellular adhesion. Eur J Cell Biol 85: 191-194.

Streuli CH, Akhtar N. 2009. Signal co-operation between integrins and other receptor systems. Biochem J 418: 491-506.

Svensson L, Howarth K, McDowall A, Patzak I, Evans R, Ussar S, Moser M, Metin A, Fried M, Tomlinson I, et al. 2009. Leukocyte adhesion deficiency-III is caused by mutations in KINDLIN3 affecting integrin activation. Nat Med 15: 306-312.

Tedder TF, Steeber DA, Chen A, Engel P. 1995. The selectins: Vascular adhesion molecules. FASEB J 9: 866-873.

Thiery JP, Acloque H, Huang RY, Nieto MA. 2009. Epithelial-mesenchymal transitions in development and disease. Cell 139: 871-890.

Turley EA, Noble PW, Bourguignon LY. 2002. Signaling properties of hyaluronan receptors. J Biol Chem 277: 4589-4592.

Vaday GG, Franitza S, Schor H, Hecht I, Brill A, Cahalon L, Hershkoviz R, Lider O. 2001. Combinatorial signals by inflammatory cytokines and chemokines mediate leukocyte interactions with extracellular matrix. J Leukoc Biol 69: $885-892$.

Vallotton P, Gupton SL, Waterman-Storer CM, Danuser G. 2004. Simultaneous mapping of filamentous actin flow and turnover in migrating cells by quantitative fluorescent speckle microscopy. Proc Natl Acad Sci 101: 9660-9665.

Vestweber D, Blanks JE. 1999. Mechanisms that regulate the function of the selectins and their ligands. Physiol Rev 79: $181-213$.

Vogel WF, Abdulhussein R, Ford CE. 2006. Sensing extracellular matrix: An update on discoidin domain receptor function. Cell Signal 18: 1108-1116.

Wang R, Stromer MH, Huiatt TW. 1998. Integrin expression in developing smooth muscle cells. J Histochem Cytochem 46: $119-126$.

Watt FM, Fujiwara H. 2011. Cell-extracellular matrix interactions in normal and diseased skin. Cold Spring Harb Perspect Biol doi:10.1101/cshperspect.a005124.

Weston JA. 1982. In memory of Michael Abercrombie. Prog Clin Biol Res 85: 1-4.

Wickström SA, Radovanac K, Fässler R. 2011. Genetic analyses of integrin signaling. Cold Spring Harb Perspect Biol doi:10.1101/cshperspect.a005116.

Winograd-Katz SE, Itzkovitz S, Kam Z, Geiger B. 2009. Multiparametric analysis of focal adhesion formation by RNAi-mediated gene knockdown. J Cell Biol 186: 423-436.

Wolfenson H, Henis YI, Geiger B, Bershadsky AD. 2009a. The heel and toe of the cell's foot: A multifaceted approach for understanding the structure and dynamics of focal adhesions. Cell Motil Cytoskeleton 66: 1017-1029.

Wolfenson H, Lubelski A, Regev T, Klafter J, Henis YI, Geiger B. 2009b. A role for the juxtamembrane cytoplasm in the molecular dynamics of focal adhesions. PLoS One 4: e4304.

Yamada KM, Cukierman E. 2007. Modeling tissue morphogenesis and cancer in 3D. Cell 130: 601-610.

Yurchenco PD. 2011. Basement membranes: cell scaffoldings and signaling platforms. Cold Spring Harb Perspect Biol doi:10.1101/cshperspect.a004911.

Zaidel-Bar R, Geiger B. 2010. The switchable integrin adhesome. J Cell Sci 123: 1385-1388.

Zaidel-Bar R, Ballestrem C, Kam Z, Geiger B. 2003. Early molecular events in the assembly of matrix adhesions at 
the leading edge of migrating cells. J Cell Sci 116: 4605-4613.

Zaidel-Bar R, Itzkovitz S, Ma’ayan A, Iyengar R, Geiger B. 2007a. Functional atlas of the integrin adhesome. Nat Cell Biol 9: 858-867.

Zaidel-Bar R, Milo R, Kam Z, Geiger B. 2007b. A paxillin tyrosine phosphorylation switch regulates the assembly and form of cell-matrix adhesions. J Cell Sci 120: $137-148$.

Zamir E, Geiger B, Kam Z. 2008. Quantitative multicolor compositional imaging resolves molecular domains in cell-matrix adhesions. PLoS ONE 3: e1901.
Zamir E, Katz M, Posen Y, Erez N, Yamada KM, Katz BZ, Lin S, Lin DC, Bershadsky A, Kam Z, et al. 2000. Dynamics and segregation of cell-matrix adhesions in cultured fibroblasts. Nat Cell Biol 2: 191-196.

Zhong C, Chrzanowska-Wodnicka M, Brown J, Shaub A, Belkin AM, Burridge K. 1998. Rho-mediated contractility exposes a cryptic site in fibronectin and induces fibronectin matrix assembly. J Cell Biol 141: $539-551$.

Zimmerman E, Geiger B, Addadi L. 2002. Initial stages of cell-matrix adhesion can be mediated and modulated by cell-surface hyaluronan. Biophys J 82: 1848-1857. 


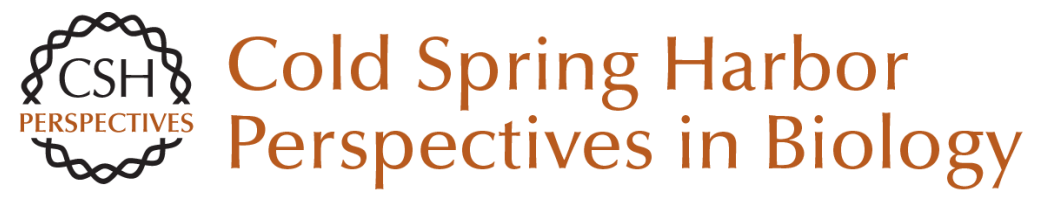

\section{Molecular Architecture and Function of Matrix Adhesions}

Benjamin Geiger and Kenneth M. Yamada

Cold Spring Harb Perspect Biol 2011; doi: 10.1101/cshperspect.a005033 originally published online March 9, 2011

\section{Subject Collection Extracellular Matrix Biology}

Extracellular Matrix in Development: Insights from Mechanisms Conserved between Invertebrates and Vertebrates Nicholas H. Brown

Extracellular Matrix Proteins in Hemostasis and Thrombosis Wolfgang Bergmeier and Richard O. Hynes

The Thrombospondins Josephine C. Adams and Jack Lawler

Cross Talk among TGF- $\beta$ Signaling Pathways, Integrins, and the Extracellular Matrix John S. Munger and Dean Sheppard

Heparan Sulfate Proteoglycans Stephane Sarrazin, William C. Lamanna and Jeffrey $D$. Esko

The Collagen Family Sylvie Ricard-Blum

Tenascins and the Importance of Adhesion Modulation

Ruth Chiquet-Ehrismann and Richard P. Tucker

Integrin Structure, Activation, and Interactions lain D. Campbell and Martin J. Humphries
Extracellular Matrix Degradation and Remodeling in Development and Disease

Pengfei Lu, Ken Takai, Valerie M. Weaver, et al.

Overview of the Matrisome--An Inventory of Extracellular Matrix Constituents and Functions Richard O. Hynes and Alexandra Naba

Integrins in Cell Migration Anna Huttenlocher and Alan Rick Horwitz

Fibronectins, Their Fibrillogenesis, and In Vivo

Functions Jean E. Schwarzbauer and Douglas W. DeSimone

Extracellular Matrix: Functions in the Nervous System

Claudia S. Barros, Santos J. Franco and Ulrich Müller

Molecular Architecture and Function of Matrix

Adhesions

Benjamin Geiger and Kenneth M. Yamada

Cell-Extracellular Matrix Interactions in Normal and Diseased Skin

Fiona M. Watt and Hironobu Fujiwara

Genetic Analyses of Integrin Signaling

Sara A. Wickström, Korana Radovanac and Reinhard Fässler

For additional articles in this collection, see http://cshperspectives.cshlp.org/cgi/collection/

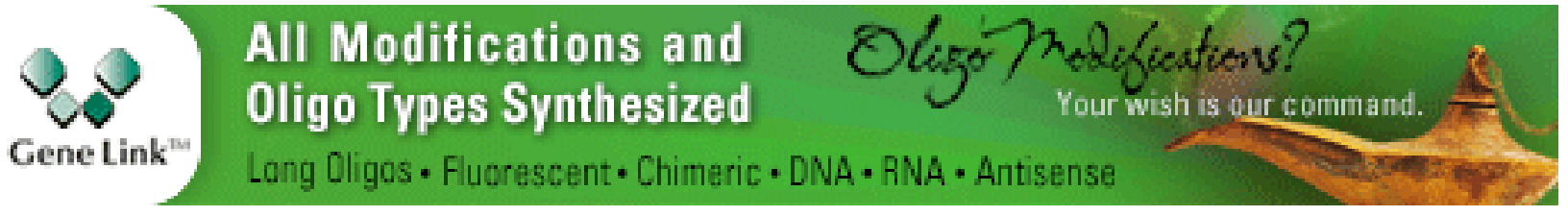

